\title{
Técnica de Alvenaria Adobe: Reprodução do Método Construtivo com e Sem o Uso de Fibra Vegetal
}

\section{Adobe Masonry Technique: Reproduction of the Construction Method with and Without the Use of Vegetable Fiber}

\author{
Mariana Aparecida Giraldellia; Osvaldo Alves Pereira*a; Samuel Felipe dos Santos ${ }^{\mathrm{b}}$; Mirela Aguiar Brasil ; Stefani \\ Karoline Teodoro Pinheiro ${ }^{\mathrm{b}}$
}

\author{
âniversidade de Cuiabá, Programa de Pós-Graduação Stricto Sensu em Ciências Ambientais. MT, Brasil.

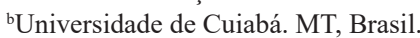 \\ *E-mail: osvaldoalvesfu@gmail.com
}

\begin{abstract}
Resumo
A técnica construtiva do adobe é um método de alvenaria em que se utilizam blocos em terra crua que possui como principal matéria prima o solo. De maneira geral, esta técnica proporcionou grandes feitos na historia da humanidade e reproduz com legitimidade um método construtivo simples, de fácil acesso e sustentável. Esta técnica bioconstrutiva é uma proposta de investimento para vários estudos, pois é um método que acompanhou a história da engenharia e da arquitetura e é possível ser aperfeiçoado podendo ser feita de várias formas possíveis com diversos agregados. Este trabalho apresenta a técnica do adobe que é uma alternativa sustentável para construções artesanais, assim como a experiência com a técnica e a mudança de comportamento para a confecção dos blocos com diferentes proporções de fibra vegetal em sua constituição, sendo que esta adição é normalmente feita para auxiliar na capacidade de resistência mecânica do bloco. Este trabalho consiste na mescla de uma revisão narrativa e a reprodução da confecção da técnica, sendo a primeira baseada em livros, artigos, seminários e demais obras cientifica que abordam o tema de construções em terra crua com destaque na técnica adobe, abordando os principais pontos para a confecção dos blocos e comparando os modos de confecção.
\end{abstract}

Palavras-chave: Construção em Terra Crua. Técnica Construtiva. Bloco de Terra Crua.

\begin{abstract}
The constructive technique of adobe is a masonry method in which blocks are used on raw earth whose main raw material is soil. In general, this technique provided great achievements in the history of humanity and legitimately reproduces a simple construction method, easily accessible and sustainable. This bioconstructive technique is an investment proposal for several studies, as it is a method that has followed the history of engineering and architecture and it is possible to be perfected and it can be done in several possible ways with different aggregates. This work presents the adobe technique, which is a sustainable alternative for artisanal constructions, as well as the experience with the technique and the change in behavior for the making of blocks with different proportions of vegetable fiber in their constitution, and this addition is usually made to assist in the mechanical strength of the block. This work consists of a mixture of a narrative review with empirical preparation, the first being based on books, articles, seminars and other scientific works that address the theme of constructions on raw earth with emphasis on the adobe technique, addressing the main points for the making of the blocks and drawing a comparison about this production.
\end{abstract}

Keywords: Raw Earth Construction. Constructive Technique. Block of Raw Earth.

\section{Introdução}

A terra foi o primeiro material utilizado e moldado pelo homem para construir sua moradia. Seu uso como matéria prima remonta há mais de 8.000 a.C., sendo está a datação de blocos de barro encontrados no Turquestão Russo (MINKE, 2012).

Conforme Santiago (2001), a utilização da técnica do adobe, técnica construtiva em se utiliza blocos de barro secos ao sol podendo ter a adição de fibras animais e vegetais, era usual no antigo Egito e Mesopotâmia. Entretanto, Santos e Bessa (2020) destacam que a utilização de terra crua nas construções brasileiras apenas teve início a partir da colonização portuguesa.

A utilização da terra crua como método construtivo caiu em desuso após a segunda grande guerra mundial, onde o aumento de construções industriais levou ao abandono das técnicas construtivas tradicionais com terra (KOUAKOU, MOREL, 2009). Entretanto houve-se um resgate das técnicas a base de terra crua devido ao seu caráter sustentável uma vez que os blocos não demandam de queima e pode-se ser confeccionado com baixo custo.

Esse estudo foi realizado com o objetivo de reproduzir esta técnica milenar, confeccionando blocos de adobe com e sem a presença de fibra de coco traçando um comparativo empírico entre a confecção sem e com a presença da fibra vegetal. Este estudo foi fundamentado em experiências práticas e revisões bibliográficas, utilizando como base pesquisas de caráter acadêmico através de consultas em livros, publicações, artigos e revistas que abordam a temática. 


\section{Desenvolvimento}

\subsection{Metodologia}

O presente artigo trata-se de uma revisão bibliográfica cujo objetivo foi identificar obras que abordassem a temática de construções em terra crua. A pesquisa foi realizada por meio de consultas aos bancos de dados do portal de periódicos CAPES/MEC, Scientific Electronic Library Online (SciELO), Google Scholar, Scopus (Elsevier), livros consagrados que abordassem o tema de bioconstruções e construções em terra. O critério de inclusão ou exclusão dos artigos se deu a partir do título, resumo e das palavras chaves, sento utilizado as seguintes palavras chaves para busca: adobe, construção em terra crua, bio construção.

\subsection{Materiais e métodos para confecção dos blocos}

O estudo foi conduzido no Laboratório de Mecânica dos Solos dos departamentos de Engenharia Civil da Universidade de Cuiabá (UNIC).

O solo utilizado foi submetido à análise granulométrica, através da combinação dos métodos de peneiramento e sedimentação conforme ABNT (1984), e determinação dos limites de Atterberg, conforme prescreve ABNT (1984).

Os blocos de adobe foram confeccionados conforme técnica descrita por Prompt (2008), sendo necessário para a modulação dos blocos de adobe 120,00 quilogramas de solo e 6,00 quilogramas de fibra de coco que foi utilizado como agregado. Estes materiais foram divididos respectivamente em três processos de fabricação tendo como variante o traço.

O primeiro processo (I) foi confeccionado sem a adição de fibra vegetal, o segundo (II) com acréscimo 5\% de fibra e o terceiro (III) com a adição de $10 \%$ de fibra na constituição dos blocos.

A forma utilizada para moldar o material possui dimensão de 240x120x50 mm de acordo com orientação da NBR 10836 (ABNT, 2013).

\subsection{Técnica Adobe}

O adobe é uma das técnicas de construção mais primitivas cujo é empregado até os dias atuais. Este método possui vasta documentação histórica, estando presente em desde o período da antiguidade, como em diversos sítios arqueológicos e em construções históricas (NEVES, 2011).

Santiago (2001) destacou a utilização do adobe nas primeiras mastabas, túmulos egípcios datados nos anos de 5.000 a.C., e, conforme Minke (2012), edifícios de adobe são conhecidos em quase toda a cultura pré-colombianas, assim como em construções na antiga China e em cidades do oriente médio.

Este método secular de construção é uma técnica construtiva em terra crua que é utilizada como alvenaria de vedações verticais. A sua confecção ocorre pela mistura de solo areno-argiloso e água sendo misturado até a obtenção de uma massa de barro homogênea e plástica, entretanto, dependendo da granulometria do solo a ser utilizado, podese fazer necessário agregar outros materiais a mistura como areia, fibras vegetais ou fibras animais. (ROTANDARO, 2011).

Conforme Cabrera e Nwaubani (1990), a incorporação de fibras naturais nesta técnica remete a antiga civilização egípcia e mesopotâmia. Esta adição era realizada para controlar a retração do e adobe durante a secagem, melhorando a força de ligação da mistura, reduzindo a densidade e diminuindo a aparência de rachadura nos blocos. (MINKE, 2012)

A técnica de confecção de blocos de adobe pode ser dívida em etapas, sendo estas a preparação da terra, confecção da massa, moldagem dos blocos, secagem e armazenamento.

\subsection{Produção dos blocos}

\subsubsection{Preparação do solo}

Rotondaro (2011) traz que o primeiro passo para a confecção dos tijolos é limpar o solo com a finalidade de remover agregados graúdos como pedras, lixos e vegetais, sendo realizado o destorroado, homogeneizado com a peneira com malha de $5 \mathrm{~mm}$ de abertura com o intuito de eliminar pedregulho e partículas graúdas do solo.

A escolha do solo a ser utilizado também é fundamental para a confecção de blocos. Conforme Minke (2012) a utilização de um barro com alto teor de argila em sua composição implica no inchaço e encolhimento da peça, levando ao surgimento de trincas e baixa resistência.

A distribuição granulométrica otimizada para a confecção de um barro adequado para a construções com terra crua devem conter aproximadamente $14 \%$ de argila, $22 \%$ de silte, $62 \%$ de areia e $2 \%$ de cascalho. Normalmente os blocos de terra crua devem ter em sua composição areia grossa, adquirindo alta porosidade e resistência a compressão com contração mínima, porem a composição deve haver quantidade suficiente de argila para criar força de ligação suficiente para o bloco ser manuseado e modelado (MINKE, 2012)

A partir dos ensaios dos granulométricos, observou-se que o solo escolhido para a confecção dos blocos possuía textura de argila. O Quadro 1 expõe o resumo granulométrico do solo utilizado e demonstra predominância de argila na composição.

Quadro 1 - Distribuição granulométrica do solo analisado em percentagem

\begin{tabular}{|c|c|c|c|c|}
\hline \multicolumn{5}{|c|}{ Resumo Granulométrico } \\
\hline $\begin{array}{c}\text { Pedregulho } \\
(\%)\end{array}$ & $\begin{array}{c}\text { Areia fina } \\
(\%)\end{array}$ & $\begin{array}{c}\text { Areia grossa } \\
(\%)\end{array}$ & $\begin{array}{c}\text { Silte } \\
(\%)\end{array}$ & $\begin{array}{c}\text { Argila } \\
(\%)\end{array}$ \\
\hline 00,00 & 00,56 & 20,62 & 20,68 & 58,14 \\
\hline
\end{tabular}

Fonte: Dados da pesquisa.

A fim de se obter uma distribuição granulométrica similar a otimizada se fez necessário a realizada a correção do solo com areia lavada média, deste modo adotando o traço 01:0.7 (solo: areia). 


\subsubsection{Confecção da massa}

A confecção da massa se deu com a adição gradativa de água e fibra ao solo corrigido, sendo amassada a mistura com os pés até se obter uma massa com consistência homogênea e plasticidade adequada para a moldagem.

Para a confecção de blocos com diferentes concentrações de fibra vegetal foram realizados três diferentes traços: I; traço livre da presença de fibra vegetal, II; traço com 5\% de fibra de coco em sua constituição e III; traço com $10 \%$ de fibra de coco presente na massa. O Quadro 2 demonstra o quantitativo de cada material adotado e o teor de umidade obtidos em cada traço e a Figura 1 apresenta as três massas obtidas.

Quadro 2 - Relação da quantidade utilizada de solo, fibra, teor de umidade para cada traço utilizado

\begin{tabular}{|c|c|c|c|}
\hline \multicolumn{4}{|c|}{ Quantitativo para Confecção das Massas } \\
\hline Traço & Solo $(\mathrm{kg})$ & Fibra $(\mathrm{kg})$ & Teor de umidade $(\%)$ \\
\hline I & 40,00 & 00,00 & 29,56 \\
\hline II & 40,00 & 2,10 & 50,55 \\
\hline III & 40,00 & 4,40 & 69,75 \\
\hline
\end{tabular}

Fonte: Dados da pesquisa.

Figura 1 - Diferentes massas de adobe em estado apropriado para modelagem, sendo a) Massa do traço I, b) Massa do traço II e c) Massa do traço III

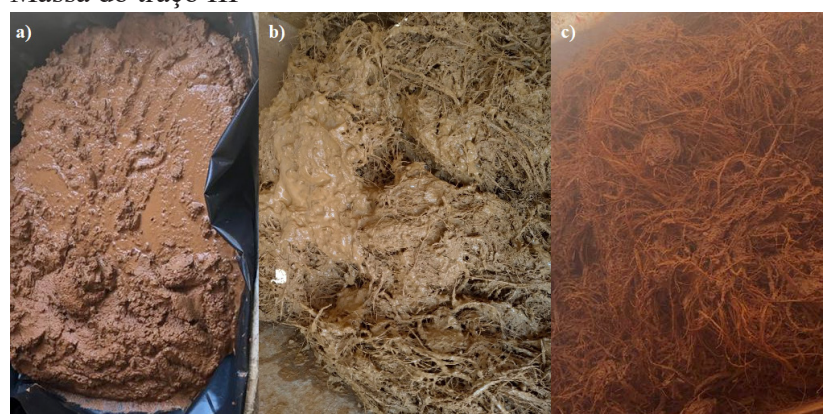

Fonte: Os autores.

A presença da fibra vegetal impactou diretamente na trababilidade no processo de homogeneização da massa, sendo que o esforço aumentou proporcionalmente com a quantidade de fibra utilizada.

A presença da fibra de coco também refletiu na quantidade de água utilizada para a obtenção das massas, sendo este refletido no teor de umidade que a massa com $10 \%$ de fibra em sua constituição utilizou mais do que o dobro de água para adquirir a homogeneização quando comparado com o traço sem fibra.

\subsubsection{Moldagem dos blocos}

De acordo com Santiago et al. (2017), não há um padrão rígido na produção dos blocos. Em geral, a fabricação e a moldagem do adobe se da pela colocação manual da massa no interior do molde através da técnica de arremesso, onde a massa pronta é arremessada nas extremidades da forma e no centro, regularizando a fase superior e desmoldando o bloco (Figura 02). Esta técnica é comumente empregada, pois a força de lançamento da massa melhora a compactação dos blocos e diminui o número de vazios.

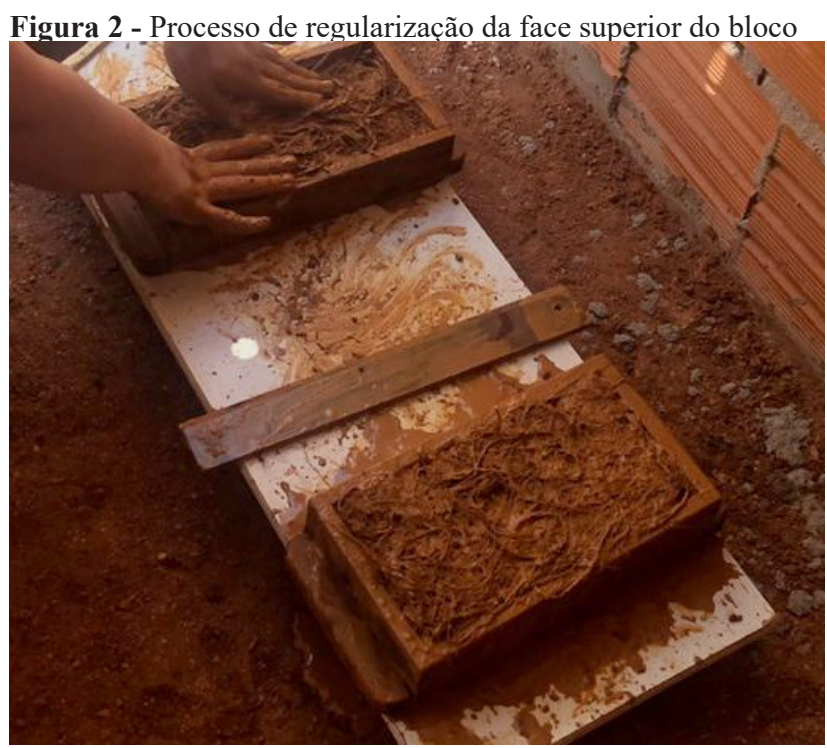

Fonte: Os autores.

A presença de fibra não impactou diretamente no número de blocos produzidos, sendo que o processo I gerou 24 blocos, o II gerou 17 blocos e o sistema III 26 blocos.

\subsubsection{Secagem, armazenamento e considerações sobre os blocos}

Conforme Prompt (2008), os blocos de adobe devem ser secos em ambiente arejado e protegido da chuva durante o período de 7 a 14 dias dependendo do clima do local. Há a recomendação de que durante o processo de secagem os blocos devem ser virados a cada dois dias, com a finalidade de seca-los uniformemente. A Figura 3 demonstram blocos de adobe durante o processo de secagem.

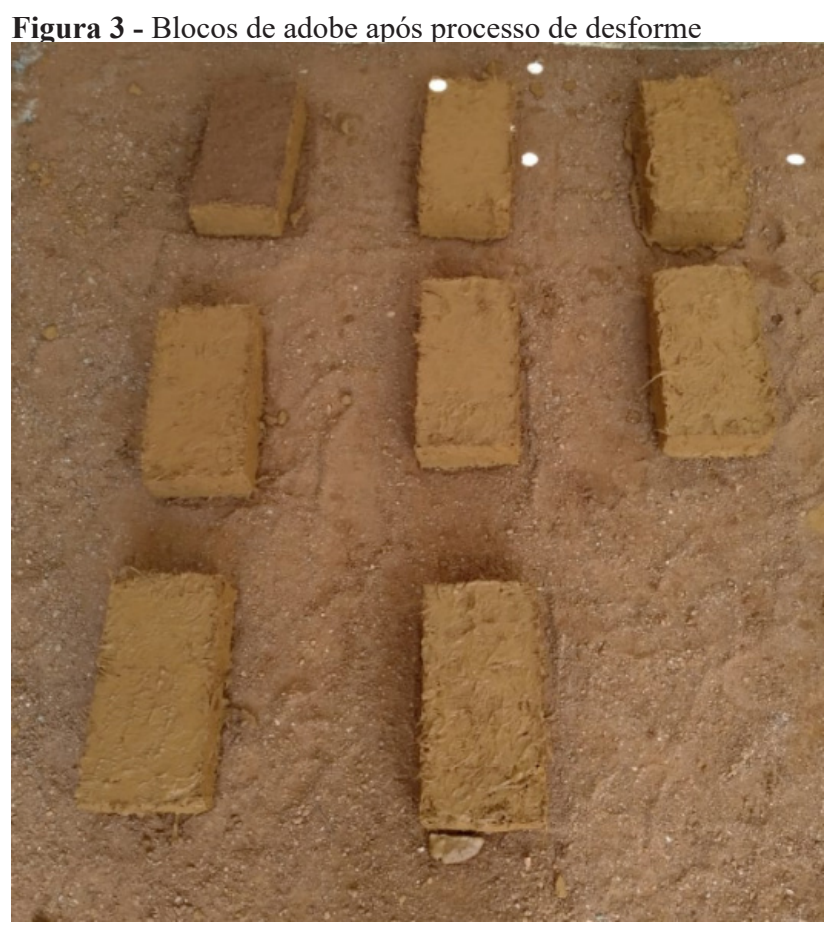

Fonte: Os autores. 
Após o período de cura foi possível realizar observações visuais de retração, onde foi observado que os blocos com a fibra de coco apresentaram menor retração em relação aos blocos pertencentes ao traço I. A Figura 4 apresenta blocos confeccionados no estudo, cada possuindo um traço diferente.

Figura 4 - Três diferentes blocos de adobe. - No canto esquerdo está um bloco do processo (I) que não possui a adição de fibras de coco, ao centro se tem um bloco do processo (II) que possui $5 \%$ de fibra na constituição e no canto direito um bloco com $10 \%$ de fibra na constituição (III)

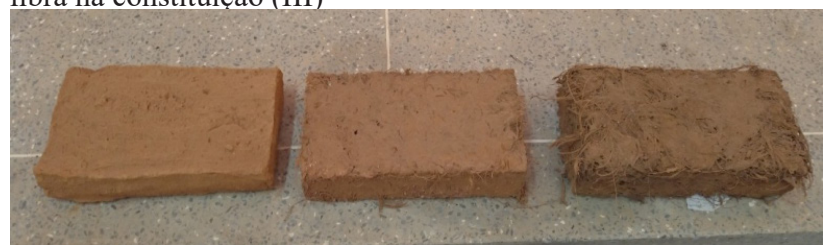

Fonte: Autores (2020)

De acordo com Ghavami et al. (1999) um dos principais objetivos do uso da fibra em métodos de terra crua é a prevenção de fissuras por retração na alvenaria. $\mathrm{O}$ processo de fissuração ocorre devido retração decorrente da rápida secagem da massa, entretanto ao se adicionar fibras vegetais o processo de retração sofre alterações, pois o a água absorvida pelo compósito é liberada de maneira mais lenta, permitindo uma perca gradativa de água durante o processo de cura.

\section{Conclusão}

Conclua-se que o adobe é um método secular, cuja utilização encontra-se presente em quase todos os continentes. A reprodução do método é simples e possui aspectos econômicos e ecológicos, sendo que a utilização de de fibras vegetais neste método construtivo demonstrou possuir maior trababilidade, consumo de água e menor retração em comparação aos blocos de adobe sem fibra vegetal.

\section{Referências}

ABNT - ASSOCIAÇÃO BRASILEIRA DE NORMAS
TÉCNICAS. NBR 6459 - Solo - Determinação do limite de liquidez - Método de ensaio. Rio de Janeiro, 1984.

ABNT - ASSOCIAÇÃO BRASILEIRA DE NORMAS TÉCNICAS. NBR 7180 - Solo - Determinação do limite de plasticidade - Método de ensaio. Rio de Janeiro, 1984.

ABNT - ASSOCIAÇÃO BRASILEIRA DE NORMAS TÉCNICAS. NBR 7181 - Solo - Análise Granulométrica Método de ensaio. Rio de Janeiro, 1984.

ABNT - ASSOCIAÇÃO BRASILEIRA DE NORMAS TÉCNICAS. NBR 10836 - Bloco de solo-cimento sem função estrutural - Análise dimensional, determinação da resistência a compressão e da absorção de água - Método de ensaio. Rio de Janeiro, 2013.

CABRERA, J. G.; NWAUBANI S. O. Experimental methods for the preparation of palm fruit and other natural fibres for use in reinforced cement composites. In: SOBRAL, H.S. Vegetable Plants and their Fibres as Building Materials. Brazil: RILEM Proceedings of the Second International Symposium, 1990.

GHAVAMI, K. et al. Behaviour of composite soil reinforced with natural fibres. Cement Concrete Compos, v.21, p.39-48, 1999.

KOUAKOU C H.; MOREL, J.C. Strength and elasto-plastic properties of non-industrial building materials manufactures with clay as a natural binder. Appl. Clay Scie., v.44, p.27-34, 2009.

MINKE, G. Building with Earth. design and technology of a sustainable architecture. Basel, Berlin: Birkhauser - Publishers for Architecture, 2012.

PROMPT, C. Curso de bioconstrução. Brasília: Ministério do Meio Ambiente, 2008.

ROTONDARO, R. Adobe. In: NEVES, C.M.M; FARIAS, O.B. (Org.). Técnicas de construção com terra. Bauru: FEB, 2011.

SANTIAGO, C.C. O solo como material de construção. Salvador: EDUFBA, 2001.

SANTIAGO, D.R. et al. técnica do adobe no cenário do século XIX em Teresina, Piauí: Documentação histórica e relevância na construção civil. In: SEMINÁRIO IBERO-AMERICANO, ARQUITETURA E DOCUMENTAÇÃO, 2017. Belo Horizonte, 2017.

SANTOS, D.P.; BESSA, S.A.L. O uso do Adobe no Brasil: uma revisão de literatura. Mix Sustentável, v.6, n.1, p. 53-66, 2020. doi: 10.29183/2447-3073.MIX2020.v6.n1.53-66 